\title{
Diet nutriment and rearing density affect the growth of black blowfly larvae, Phormia regina (Diptera: Calliphoridae)
}

\author{
Paul W.C. GREEN ${ }^{1,2, *}$ Monique S.J. SIMMONDS ${ }^{1}$ and Wally M. BLANEY ${ }^{2}$ \\ ${ }^{1}$ Jodrell Laboratory, Royal Botanic Gardens, Kew, Richmond, Surrey, TW9 3AB, UK \\ ${ }^{2}$ School of Biological and Chemical Sciences, Birkbeck College, Malet Street, London WC1E 7HX, UK
}

Key words. Phormia regina, Calliphoridae, protein, carbohydrate, nutrition, group rearing

\begin{abstract}
Larvae of Phormia regina (Meigen) (Diptera: Calliphoridae) were reared, in isolation, upon either lamb's liver or meridic diets that varied in protein- and carbohydrate-content. An artificial diet containing 53\% protein (by mass of dry ingredients) resulted in the heaviest $P$. regina pupae and shortest development time when compared with larvae reared upon lamb's liver and all other diets. In diets where the concentration of protein was less than that of carbohydrate, the level of carbohydrate became important. In a diet containing $22.6 \%$ protein it was neither the diet with the highest $(51 \%)$ nor lowest $(17 \%)$ concentration of carbohydrate that adversely affected development. Specifically, an intermediate level of carbohydrate $(33.9 \%)$ resulted in an extended larval period, together with increased mortality and reduced pupal weights. Larvae reared in groups of 10 on either liver or a diet containing $53 \%$ protein were heavier than those reared in isolation. Group-rearing hastened development on liver, but not on the meridic diet. The results are discussed in relation to the nutritional ecology of saprophagous calliphorids.
\end{abstract}

\section{INTRODUCTION}

Phormia regina, the black blowfly, is primarily a saprophagous species that feeds upon highly proteinaceous foods during the larval stage. Typically, a diet consisting of $98 \%$ protein is regarded as a requirement for optimum growth of $P$. regina larvae (Singh, 1977; Simpson \& Raubenheimer, 1993). Diets that contain less protein can cause a reduced rate of weight gain by groups of $P$. regina larvae (Brust \& Fraenkel, 1955) together with increased development times (Hill et al., 1947) and larval mortality (Hill et al., 1947; Brust \& Fraenkel, 1955; McGinnis et al., 1956). However, diets that contain much lower levels of protein can be used to rear $P$. regina larvae in the laboratory (Green, 1999). Extensive studies on $P$. regina adults have shown that individuals are able to maintain nutrient balance by increasing intake of either protein-, amino-acid- or carbohydrate-limited diets or, conversely, by decreasing intake where these nutrients are excess to requirements (Dethier, 1976). The aim of this study was to investigate whether isolated larvae of $P$. regina could gain weight and pupate upon diets with varying nutrient levels. A comparison was also made between the development of isolated larvae and groups of larvae on some of the diets.

\section{MATERIALS AND METHODS}

\section{Diets}

The proportions of casein (technical, from bovine milk), and sucrose (both Sigma Chemical Co., UK) in an artificial meridic diet were modified to alter the concentration of protein (15 to $52 \%$ ) and carbohydrate ( 17 to $51 \%$ ) (Table 1 , diets 1 to 5 ). The amounts of casein and sucrose in diets were varied in diets 1 to 4 and casein was omitted from diet 5 (Table 1). The quantity of cellulose (Sigma Chemical Co., UK) added to diets was also altered to maintain the mass of dry ingredients. An agar (Fisons, $\mathrm{UK}$ ) and distilled water mixture was boiled in a $650 \mathrm{~W}$ microwave oven before dried, inactive yeast powder (Philip Harris Biological, UK) and the remaining ingredients were added with cold distilled water. Diets were mixed thoroughly and poured into $130 \mathrm{ml}$ disposable plastic containers $(1.5 \mathrm{~cm}$ high $\times 10.5$ $\mathrm{cm}$ diam.) (Bellaplast Polarcup ${ }^{\circledR}$, Roundstone Catering, UK). Once set and cooled the diets were presented to larvae. The control diet, lamb's liver, was obtained from a local supermarket.

\section{Insects}

A colony of Phormia regina (Meigen) was maintained in the School of Biological and Chemical Sciences, Birkbeck College in a room measuring $2.5 \times 1.1 \times 1.3 \mathrm{~m}(\mathrm{H}, \mathrm{W}, \mathrm{D})$ and subject to a $12: 12 \mathrm{~h}$ light dark cycle, $60 \pm 10 \%$ relative humidity and a constant temperature of $23 \pm 2^{\circ} \mathrm{C}$. The room was ventilated via $30 \mathrm{~cm}$ square ducting that opened into an adjacent room. Groups of 150 eggs were placed upon $250 \mathrm{ml}$ of a meridic casein $(36$ $\left.\mathrm{gl}^{-1}\right)$, agar $\left(12 \mathrm{gl}^{-1}\right)$ and yeast $\left(100 \mathrm{gl}^{-1}\right)(\mathrm{CAY})$ diet in 1 litre "Kilner" jars and larvae were reared to pupation.

Alternatively, 5 days after egg-placement, larvae were transferred to 1.5 litre Stewart ${ }^{\mathbb{}}$ sandwich boxes that contained a 2 $\mathrm{mm}$ layer of fine vermiculite granules to absorb moisture from the larvae. After $10 \mathrm{~min}$ the vermiculite was brushed off the larvae, using a soft-bristle paint brush, and larvae were weighed. To ensure a uniformity of the experimental population only those larvae that weighed between 20 and $22 \mathrm{mg}$ were selected.

\section{Method}

Plugs of diet $1(1.5 \mathrm{~cm}$ diam. $\times 1.5 \mathrm{~cm}$ high $)$ were removed from the set diet using a cork-borer and placed into each cell of a 25-way Sterilin culture dish. Each division of the dish was $5 \mathrm{~cm}^{3}$, and each plug of diet occupied $2.7 \mathrm{~cm}^{3}$, so that $2.3 \mathrm{~cm}^{3}$ of free space remained. A single pre-weighed larva was placed into each cell and the dish was sealed with tissue paper under the lid. This process was repeated for pieces of liver ( 2 gram), diets 2 , $3,4(\mathrm{n}=25)$ and $\operatorname{diet} 5(\mathrm{n}=20)$.

\footnotetext{
* Corresponding author. E-mail: Paul.Green@rbgkew.org.uk
} 
TABLE 1. Ingredients and nutrient contents of diets presented to isolated second instar $P$. regina larvae.

\begin{tabular}{lcccccc}
\hline & \multicolumn{3}{c}{ Concentration of component in diet, g/litre } & \multicolumn{2}{c}{$\%$} \\
\hline Diet & Casein $^{\alpha}$ & Sucrose $^{b}$ & Cellulose $^{c}$ & Yeast $^{d}$ & $\mathrm{P}$ & $\mathrm{C}$ \\
\hline Lamb's & & & & & $73.9^{e}$ & $6.5^{e}$ \\
liver & & & & & & \\
1 & 0 & 0 & 82.5 & 83.3 & 22.6 & 17 \\
2 & 0 & 60 & 22.5 & 83.3 & 22.6 & 51 \\
3 & 60 & 0 & 22.5 & 83.3 & 52.2 & 17 \\
4 & 30 & 30 & 22.5 & 83.3 & 37.9 & 33.9 \\
5 & 0 & 30 & 52.5 & 83.3 & 22.6 & 33.9 \\
\hline
\end{tabular}

Agar was incorporated into each diet at a concentration of 10 $\mathrm{gl}^{-1} \cdot \mathrm{P}=$ protein and $\mathrm{C}=$ carbohydrate.

${ }^{a}$ casein $=90 \%$ protein and $10 \%$ fat.

${ }^{b}$ sucrose $=100 \%$ carbohydrate.

cellulose is indigestible to $P$. regina.

${ }^{d}$ yeast $=48 \%$ protein and $36 \%$ carbohydrate

${ }^{e}$ liver also contains $18 \%$ fat and $1.3 \%$ cholesterol. Data taken from "Nutribase SR13 Navigator"C 1986-2001, Cybersoft Inc. (http://www.Nutribase.com/).

Preliminary experiments indicated that isolated larvae did not burrow into liver but fed on the liquid exuding from it. Groups of $P$. regina larvae commonly reduce lamb's liver to a liquid. When liquefied material is ingested dark patches of the gut are visible through the cuticle. To observe if larvae reared in groups develop differently from isolated larvae, an additional experiment was set up using groups $(\mathrm{n}=3)$ of larvae $(\mathrm{n}=10)$ reared in plastic Petri dishes $(9 \mathrm{~cm}$ diam.) upon either $20 \mathrm{~g}$ pieces of liver or $30 \mathrm{ml}$ aliquots of diet 3 . All of the Sterilin culture dishes and Petri dishes were kept in the culture-room for the duration of the experiment. Dishes were checked every day for pupae and dead larvae. Pupae were removed, dried in vermiculite, cleaned and weighed. Dead larvae were discarded. Diets were replenished every two days. The experiment concluded when all the larvae had either died or pupated. Pupal weights and the times spent on experimental diets before pupation ("development time") were compared among the eight experiments using the KruskalWallis test $(\mathrm{KW})$ and between pairs of diets using the Wilcoxon-Mann-Whitney test (WMW). Mortalities were compared as Poisson counts (Parker, 1988). Minitab v. 12.22 (Minitab Inc.) was used for the KW and WMW analyses.

\section{RESULTS}

The nutrient content of the diets affected the development times and pupal weights of larvae (Table 2; KW, P $\leq 0.001$ for each variable). A comparison of data for diets 1 and 3 show that as protein content in a diet increased (from 22.6 to $52.2 \%$ ), with a constant level of carbohydrate $(17 \%)$ there was an increase in pupal weights and a decrease in development time of isolated larvae. Similarly, development times were reduced with an increase in protein content from 22.6 (diet 5) to $37.9 \%$ (diet 4) with a constant level of carbohydrate (33.9\%), although in this instance pupal weights were unaffected. Larvae exposed to diets that contained $22.6 \%$ protein (diets 1,2 and 5) were affected by the varying carbohydrate concentrations in these diets. However, larvae presented with diets 1 (17\% carbohydrate) and 2 (51\% carbohydrate) developed more quickly (WMW, $\mathrm{P} \leq 0.05$ ) into heavier pupae (WMW, $\mathrm{P} \leq 0.05$ ) when compared with larvae exposed to the intermediate concentration of carbohydrate $(33.9 \%)$ in diet 5 (Table 2). Larvae reared in isolation upon lamb's liver were neither the heaviest nor the first to pupate (Table 2). However, the individuals reared in groups that were presented with lamb's liver were more than $14 \mathrm{mg}$ heavier at pupation than those reared in isolation ( $W M W, P \leq 0.01$; Table 2) and were also significantly heavier than those reared in groups upon diet 3 (WMW, $\mathrm{P} \leq 0.01$; Table 2). Therefore, groups of larvae are able to extract more nutriment from liver than can isolated larvae. In contrast, there was less of an increase in pupal weights for those larvae reared in groups upon diet 3 (approx. $3 \mathrm{mg}$ ) (WMW, $\mathrm{P} \leq 0.05$; Table 2) and development time was not different from that of isolated larvae (WMW, $\mathrm{P} \geq 0.05$; Table 2). Thus, when compared with those larvae reared in isolation, groups of larvae obtain some nutritional benefit when reared upon an artificial diet (diet 3), although to a lesser degree than those presented with lamb's liver.

\section{DISCUSSION}

Data have shown that the pupal weights and development times of isolated $P$. regina larvae can be affected by the amount of protein and carbohydrate in their diets. If

TABLE 2. Development times, pupal weights and percentage mortality of $P$. regina larvae when reared in isolation or in groups ${ }^{a}$ upon diets that varied in their protein and carbohydrate content.

\begin{tabular}{lccc}
\hline Diet & Mean development time, days $\pm \mathrm{SEM}^{b}$ & Mean pupal weights, $\mathrm{mg} \pm \mathrm{SEM}^{b}$ & ${\text { Percentage mortality, } \pm \mathrm{SEM}^{b}}^{\text {Lamb's liver }}$ \\
& $8 \pm 0.2 \mathrm{~b}$ & $41 \pm 1.6 \mathrm{~b}$ & $32 \mathrm{a}$ \\
1 & $(5 \pm 0.4 \mathrm{a})$ & $(56 \pm 1.8 \mathrm{e})$ & $(30 \pm 5.8 \mathrm{a})$ \\
2 & $7 \pm 0.3 \mathrm{~b}$ & $39 \pm 1.3 \mathrm{~b}$ & $20 \mathrm{a}$ \\
3 & $8 \pm 0.5 \mathrm{~b}$ & $40 \pm 1.6 \mathrm{~b}$ & $36 \mathrm{a}$ \\
& $5 \pm 0.1 \mathrm{a}$ & $46 \pm 1.3 \mathrm{c}$ & $(23 \pm \mathrm{a}$ \\
4 & $(5 \pm 0.2 \mathrm{a})$ & $(49 \pm 1.3 \mathrm{~d})$ & $28 \mathrm{a}$ \\
5 & $8 \pm 0.4 \mathrm{~b}$ & $27 \pm 1.6 \mathrm{a}$ & $50 \mathrm{a}$ \\
\hline
\end{tabular}

${ }^{a}$ Figures in parenthesis refer to those larvae reared in groups of 10 . Larvae weighed between 20 and $22 \mathrm{mg}$ at the start of the experiments.

${ }^{b}$ Differences between development times or between pupal weights were compared with the Wilcoxon-Mann-Whitney test. Mortalities were compared as Poisson counts. Different letters in a column indicate significant differences, $\mathrm{P} \leq 0.05$. 
heavy pupae are considered as an indicator of an optimum diet, then blowfly larvae exposed to diet $3(52.2 \% \mathrm{P}: 17 \%$ C) could be said to have ingested the level, balance and availability of nutriment that is most appropriate, among the diets tested, for isolated larvae of $P$. regina. Diet 3 had the highest protein content and the lowest level of carbohydrate tested. Thus, among the meridic diets tested, a high concentration of protein together with a low level of carbohydrate is more nutritious for larvae of $P$. regina. A comparison between diets $1(22.6 \% \mathrm{P}: 17 \% \mathrm{C})$ and 3 $(52.2 \% \mathrm{P}: 17 \% \mathrm{C})$ supports this conclusion, since the greater concentration of protein in diet 3 resulted in shortened development time and increased pupal weights.

Larvae reared upon diets $1,2,4$ and 5 were exposed to a low protein content $(22.6 \%)$ when compared with diet 3. Insects can respond to reduced nutrient levels in their diets by increasing either the rate of ingestion or the amount ingested (Slansky \& Scriber, 1985; Simpson et al., 1988; Slansky Jr. \& Wheeler, 1989, 1992). However, increased consumption of diet by $P$. regina larvae was not quantified as the amount of diet ingested could not be measured. Alternatively, $P$. regina larvae reared upon diets 1, 2, 4 and 5 may have fed for a longer period of time, resulting in an extension of the larval period when compared with those larvae reared upon diet 3. Hamano et al. (1994) found that the larval stadia of Bombyx mori (L.) could be extended by nutrient-restriction, provided that the food contained sufficient nutriment to keep the larvae alive. Blowfly larvae are similarly able to feed for a longer period, and therefore extend their larval stage, in order to obtain sufficient nutriment for pupation (Žd'árek \& Sláma, 1972). However, many insect larvae require a certain amount of time spent feeding before pupation (Sehnal, 1985). Saunders and Bee (1995) suggested that the successful pupation of larvae of Calliphora vicina Robineau-Desvoidy was dependent on larvae feeding for a period of between 3 and $10 \mathrm{~h}$ during the third instar. Our data indicate that some larvae of $P$. regina are able to extend their larval stage in an attempt to obtain sufficient nutriment.

Increased protein in a diet did not always enhance development of $P$. regina larvae. Diets 4 and 5 contained the same amount of carbohydrate $(33.9 \%)$, but diet 4 contained $15.3 \%$ more protein than diet 5 . Larvae did develop more rapidly on diet 4 than on diet 5, but pupal weights were similar. This indicates that the greater protein content in diet 4 does not sufficiently improve nutriment to affect pupal weights.

Wimer (1969) analysed the concentrations of carbohydrates in the haemolymph of third instar $P$. regina and found that the levels of free glucose declined as the larvae aged. Ingestion of high levels of carbohydrate might place stress on the metabolism of larvae as they attempt to remove excess carbohydrates from the haemolymph. However, larvae developed more rapidly into heavier pupae on diets 1 and 2: the two diets with the lowest and highest carbohydrate contents, respectively. Therefore, a $33.9 \%$ of carbohydrate extends the larval phase and reduces the pupal weights attained by $P$. regina larvae.
The osmolarity of an ingested diet can affect the development and mortality of calliphorid larvae, such as screwworm (Gingrich, 1965) and $P$. regina (Cheldelin \& Newburgh, 1959). Furthermore, a 34\% concentration of sucrose in a diet has been found to cause significant mortality of first and second instar $P$. regina. Carbohydrate levels of around $40 \%$ might disrupt the osmoregulation of $P$. regina resulting in an increased larval period and decreased pupal weights (Cheldelin \& Newburgh, 1959).

Rearing larvae in groups of 10 larvae per Petri dish enhanced the pupal weights attained (liver and diet 3 ) and reduced the development time (liver). Hobson (1932a, 1932b) and Mackerras \& Freney (1933) described how groups of Lucilia sericata (Meigen) and Lucilia cuprina (Wiedemann), respectively, liquefy muscle by the mechanical action of their mouthparts and by their tryptic and alkaline secretions. The action of groups of larvae generates metabolic heat; neutralises the acidity associated with bacterial growth and pre-digests the substratum (Hobson, 1932a, 1932b; Mackerras \& Freney 1933). Groups of ten larvae would produce a greater volume exudate than an isolated larva. Thus, the tryptic and alkaline secretions and excretions would spread over a larger area, pre-digesting more of the diet. The nutriment in liver and diet 3 would, therefore, be more easily digested and assimilated by individuals within a group, than by isolated larvae.

We have shown in this study that isolation of larvae can result in slowed growth and reduced pupal weights for a saprophagous blowfly species due to a lack of the beneficial effects associated with group-rearing. Similarly, overcrowding of blowfly larvae can result in slowed larval development, smaller pupae and increased mortality (Ulyett, 1950; Hanski, 1987; Saunders \& Bee, 1995). However, reduced nutriment per larva (Hanski, 1987; Prinkkilä \& Hanski, 1995) and disruption of normal feeding patterns (Dallwitz, 1987), rather than a reduced ability to digest the substratum, are responsible for the detrimental effects of overcrowding.

Larvae reared in groups of ten upon liver were heavier than those presented with diet 3. The difference between the effects of liver and diet 3 on the development of groups of $P$. regina larvae reflects the different nutriment in these two diets. Liver contains $22.7 \%$ more protein than diet 3 and higher concentrations of other nutrients, such as cholesterol: an insect vitamin (Dadd, 1985).

In conclusion, in the absence of nutrient restriction, individual larvae of $P$. regina within groups develop more rapidly into heavier pupae when compared with isolated larvae. However, individual $P$. regina larvae within a population are able to gain weight and survive to pupation on nutriment-restricted diets. Therefore, some larvae of $P$. regina would pupate in situations where competition is intense and/or when nutriment is limited (e.g. carcasses). Small pupae and small adults would result from larvae subjected to nutrient restriction. An ability to produce small adults is an adaptation to patchy and resource-limited habitats such as carcasses (Hanski, 1987). Whilst small adult blowfly can still disperse, they 
are less fecund (Williams \& Richardson, 1983). Stoffolano Jr. et al. (2001) suggested that larval nutrition, rather than genetics, influences the size of $P$. regina adults. We have shown that larval nutrition is important in larval development although there might also be a genetic component since some larvae appear more predisposed to survive nutrient restriction than others.

ACKNOWLEDGEMENTS. The authors are grateful to Mr. M. Cullum (Birkbeck College) for technical assistance.

\section{REFERENCES}

BrUSt M. \& Fraenkel G. 1955: The nutritional requirements of the larvae of a blowfly, Phormia regina (Meigen). Physiol. Zool. 28: 186-204.

Cheldelin V.H. \& Newburgh R.H. 1959: Nutritional studies on the blowfly. Ann. New York Acad. Sci. 77: 373-383.

DADD R.H. 1985: Nutrition: organisms. In: Kerkut G.A. \& Gilbert L. I. (eds): Comprehensive Insect Physiology, Biochemistry and Pharmacology, Volume IV. Pergamon Press, Oxford, UK., pp. 313-390.

DALLwITZ R. 1987: Density independence of survival in myiasis breeding of Lucilia cuprina (Wiedemann) (Diptera: Calliphoridae). Bull. Entomol. Res. 77: 171-176.

Dethier V.G. 1976: The Hungry Fly: A Physiological Study of the Behavior Associated With Feeding. Harvard University Press, Cambridge, MA, USA, 512 pp.

GINGRICH R.E. 1965: Nutritional studies on screw worm larvae with chemically defined media. Ann. Entomol. Soc. Am. 57: 351-360.

GreEN P.W.C. 1999: Factors Affecting the Development of Phormia regina (Meigen) (Diptera: Calliphoridae). Ph. D. dissertation, University of London, UK.

Hamano K., Ikeda A. \& Shen W. 1994: Relationship between food consumption and molting of the silkworm, Bombyx mori. Proc. Japan Acad. 70B: 146-150.

HANSKI I. 1987: Nutritional ecology of carrion- and dungfeeding insects. In: Slansky F. Jr. \& Rodriguez J.G. (eds): Nutritional Ecology of Insects, Spiders, Mites and Related Invertebrates. John Wiley, New York, USA, pp. 837-884.

Hirl D.L., Bell V.A. \& Chadwick L.E. 1947: Rearing of the blowfly, Phormia regina, on a sterile synthetic diet. Ann. Entomol. Soc. Am. 40: 213-216.

Hobson R.P. 1932a: Studies on the nutrition of blow-fly larvae II. Role of the intestinal flora in digestion. J. Exp. Biol. 9: 128-138.

Hobson R.P. 1932b: Studies on the nutrition of blow-fly larvae III. The liquefaction of muscle. J. Exp. Biol. 9: 359-365.

Mackerras M.J. \& Freney M.R. 1933: Observations on the nutrition of maggots of Australian blow-flies. J. Exp. Biol. 10: 237-246.
McGinnis A.J., Newburgh R.W. \& Cheldelin V.H. 1956: Nutritional studies on the blowfly, Phormia regina (Meigen). $J$. Nutrit. 58: 309-323.

PARKER R.E. 1988: Introductory Statistics for Biology. Edward Arnold, London, UK, 122 pp.

PrinkKILÄ M.-L. \& Hanski I. 1995: Complex competitive interactions in four species of Lucilia blowflies. Ecol. Entomol. 20: $261-272$.

Saunders D.S. \& BeE A. 1995: Effects of larval crowding on size and fecundity of the blowfly, Calliphora vicina (Diptera: Calliphoridae). Eur. J. Entomol. 92: 615-622.

Sehnal F. 1985: Morphology of insect development. Annu. Rev. Entomol. 30: 89-109.

Simpson S.J. \& Raubenhermer D. 1993: A multi-level analysis of feeding behaviour: the geometry of nutritional decisions. Phil. Trans. R. Soc. Lond. (B) 342: 381-402.

Simpson S.J., Simmonds M.S.J., Blaney W.M. \& Jones J.P. 1988: Compensatory diet selection occurs in larval Locusta migratoria but not Spodoptera littoralis after a single deficient meal during ad libitum feeding. Physiol. Entomol. 15: 235-242.

Singh P. 1977: Artificial Diets for Insects, Mites and Spiders. IFI/Plenum Data, New York. USA, 594 pp.

Slansky F. JR. \& SCRIBER J.M. 1985: Food consumption and utilisation. In: Kerkut G.A. \& Gilbert L.I. (eds): Comprehensive Insect Physiology, Biochemistry and Pharmacology, Volume IV. Pergamon Press, Oxford, UK., pp. 87-163.

SLANSKY F. JR. \& WhEELER G.S. 1989: Compensatory increases in food consumption and utilization efficiencies by velvetbean caterpillars mitigate impact of diluted nutrients on growth. Entomol. Exp. Appl. 51: 175-187.

SlansKy F. JR. \& WheEleR G.S. 1992: Caterpillars' compensatory feeding in response to diluted nutrients leads to a toxic allelochemical dose. Entomol. Exp. Appl. 65: 171-186.

Stoffolano J.G. JR., Gonzalez E.Y., Sanchez M., Kane J., Velázquez K., Oquendo A.L., Sakolsky G., Schafer P. \& YIN C.-M. 2000: Relationship between size and mating success in the blowfly Phormia regina (Diptera: Calliphoridae). Ann. Entomol. Soc. Am. 93: 673-677.

UlLYETT G.C. 1950: Competition for food and allied phenomena in sheep blowfly populations. Phil. Trans. R. Soc. Lond. (B) 234: 77-137.

Williams H. \& RichaRdson A.M.M. 1983: Life history responses to larval food shortages in four species of necrophagous flies (Diptera: Calliphoridae). Austr. J. Ecol. 8: 257-263.

WIMER L.T. 1969: A comparison of the carbohydrate composition of the haemolymph and fat body of Phormia regina during larval development. Comp. Biochem. Physiol. 29: 1055-1062.

Ž̉́ÁREK J. \& SLÁMA K. 1972: Supernumerary larval instars in cyclorrhaphous Diptera. Biol. Bull. 142: 350-357.

Received October 8, 2001; revised November 5, 2002; accepted November 6, 2002 